\title{
Koronavaksinasjon: Frykt for sprøyter kan dempes med enkle tiltak
}

Grundige forberedelser, godt informert samarbeid og respekt for den enkeltes frykt kan dempe smerteopplevelsen, øke kontrollen og forebygge negative opplevelser hos den som skal vaksineres.

Atle Dyregrov

Professor og psykologspesialist

Senter for krisepsykologi, Universitetet i Bergen og Klinikk for krisepsykologi

Torkil Berge

Psykologspesialist

Voksenpsykiatrisk avdeling, Diakonhjemmet Sykehus

Marianne Haagensen Øien

Anestesisykepleier

Universitetssykehuset Nord-Norge

Mads Gilbert

Overlege dr.med.

Akuttmedisinsk klinikk, Universitetssykehuset Nord- Norge

\begin{tabular}{|l|l|l|l|l|l|}
\hline Angst & Forebygging \\
\hline
\end{tabular} 
Enkle tiltak og gode rutiner kan forebygge og dempe frykt for sprøyter, kanyler og nålestikk. Vi har samlet noen råd som kan brukes nå som mange mennesker snart skal vaksineres mot covid-19 i Norge. Sykepleiere er en helt sentral målgruppe.

Det vil finnes mennesker med varierende grad av frykt for sprøytestikk - fra engstelse og uro til lammende fobi - blant dem som nå skal vaksineres.

Slik frykt kan medvirke til at mange unnlater å la seg vaksinere. Vi har derfor samlet noen råd som kan brukes nå som mange mennesker snart skal vaksineres mot covid-19 i Norge (1).

\section{Om frykt for nåler og sprøytefobi}

En oversiktsartikkel basert på 119 originalartikler viste at de fleste barn er redde for sprøytestikk (2). Blant voksne i alderen 20 til 40 år var utbredelsen av frykt for sprøyter fra 20 til 30 prosent.

Frykt for nåler førte til at 16 prosent av de spurte voksne hadde unngått å ta vanlig influensavaksine. Det samme hadde 27 prosent av spurte sykehusarbeidere, 18 prosent av de som jobber i pleieinstitusjoner, og 8 prosent av helsepersonell på sykehus (2).

Mildere frykt for og motvilje mot å ta sprøyter er altså vanlig. En fjerdedel blant menn og nærmere tre fjerdedeler blant kvinner opplevde frykt for nålestikk i en australsk studie (3). Blant dem som fryktet nåler, sa 64 prosent at de ville unngå å ta en fremtidig influensavaksine, mot rundt 20 prosent blant de unders $\varnothing$ kte som ikke hadde en slik frykt.

\section{三 «Ikke sjelden har vaksinasjonen skjedd på en unødig brutal og barnefiendtlig måte.»}

For noen blir angsten så sterk og hemmende at den kan betegnes som en fobi. Dette gjelder anslagsvis 3-4 prosent av den voksne befolkningen $(4,5)$. Hos gravide er det rapportert en forekomst på over 7 prosent (6).

\section{Barn kan lære sprøytefrykt}


Opphavet til frykten for nålestikk er ofte vonde opplevelser fra egen vaksinasjon og andre typer sprøytestikk i

barndommen. Ikke sjelden har vaksinasjonen skjedd på en unødig brutal og barnefiendtlig måte. Jo mer smerte, desto mer negativt blir minnet om stikket. Barn venner seg heller ikke til smertefulle prosedyrer.

Barn kan også ha lært slik frykt på en indirekte måte ved å se at andre blir redde i situasjonen, eller ved at barnet har blitt fortalt at stikk er farlig og smertefullt. Det er større arvelighet av sprøyte- og blodfobi enn av andre fobier (7).

\section{Reaksjonene kan være intense og pinlige}

Under vaksinasjonen vil personer med sprøytefobi frykte den sterke følelsesmessige reaksjonen som de vet vil komme ved synet av sprøyten, en reaksjon som i seg selv er intenst ubehagelig. Dessuten kan de være redde for å besvime, miste kontrollen eller gjøre noe som er pinlig og flaut når de rammes av redsel. Noen reagerer også med intens avsky, blir svimle eller er engstelige for at de skal bli kvalme og kaste opp (8).

De som har en sterk frykt for å se blod (blodfobi), kan få en paradoksal fysiologisk reaksjon ved synet av sprøyter og blod, med blodtrykksfall og $\varnothing$ kt risiko for å besvime (9).

Svimmelheten forsterkes hvis man hyperventilerer. For noen varer svimmelheten lenge og fører til utmattelse i flere timer etterpå.

\section{God praksis har effekt}

Det er veletablert og god klinisk praksis at barn på sykehus med frykt for nåler skal behandles omsorgsfullt og med god planlegging når de må ha sprøyte, kanyle eller ta blodprøver (10). Anbefalingen er å bruke en lokalbedøvende krem, la barnet finne en behagelig stilling med kroppskontakt hos en trygg voksen, og aldri bruke fysisk makt for å holde barnet fast. En alderstilpasset distraksjon kan også være nyttig.

Tilsvarende er også effektivt for voksne: Grundige forberedelser, enkle smertereduserende tiltak, godt informert samarbeid og respekt for den enkeltes frykt.

\section{Fire enkle tiltak mot frykt og smerte}


Vaksineinjeksjoner utløser en akutt, men begrenset

fysiologisk smerte som formidles av smertereseptorer i hud og underhud. Smerten utløses på to tidspunkter: Når sprøytespissen punkterer huden og vevet under, og når vaksinevæsken injiseres inn i vevet (11).

Enkle tiltak kan dempe smerteopplevelsen, $\varnothing$ ke kontrollen og forebygge negative opplevelser hos den som skal vaksineres, særlig hos dem som frykter stikket:

- Lytt: Ta frykten på alvor og lytt til dem som er redde.

- Informer: Gi ærlig, grundig og saklig informasjon på forhånd.

- Opptre rolig: Vær rolig og trygg, og vis respekt for den enkeltes frykt.

- Lokalbedøvelse: Bruk lokalbedøvende salve ved sterk og lammende frykt for stikk.

Forklar formålet med vaksinasjonen og lytt til innvendinger og spørsmål. En kort og fokusert samtale kan etablere tillit og et godt emosjonelt klima rundt prosedyren. Informasjonen du gir, kan være enkel:

«Vi er glade for at du vil la deg vaksinere. Vaksinasjonen vil hjelpe kroppen med å unngå å bli syk hvis du skulle få covidviruset, og den kan også redusere risikoen for å smitte andre. Helsedirektoratet $\varnothing$ nsker at alle voksne skal vaksineres.

Det tar tid før vaksinen virker og infeksjonsrisikoen blir redusert, så du må fortsatt holde avstand, vaske hendene og holde deg hjemme hvis du skulle bli syk, også etter at du er vaksinert.»

For dem som har en sterk frykt for vaksinasjon, anbefaler vi å finne ut hva den enkelte der og da tenker og frykter vil skje. Noen har fantasier om at nålen kan brekke inni dem eller bli stående fast. Misforståelser oppklares gjennom en god samtale med lyttende helsepersonell.

\section{Forklar prosedyren saklig og sannferdig}

Forklar selve vaksinasjonsprosedyren. Om mulig, gjør det dagen før til dem med stor frykt. Da kan du også avtale nødvendige smertereduserende forberedelser som bruk av lokalbedøvende salve. Du kan også dele ut Folkehelseinstituttets enkle og nyttige informasjonsark om vaksinen til publikum (12). 
Under en slik forberedende samtale bør du ikke si: «Det er bare et lite stikk.» Du kan heller forklare det slik:

«Når du kommer til lege eller sykepleier for å bli vaksinert, kan det hende du må vente en stund. Når det blir din tur, kan du velge hvilken arm du vil ha vaksinen $i$. De fleste får stikket uten bedøvelse, men etter avtale kan du først få en bedøvelseskrem, som smøres på og dekkes med et plaster om lag en time før du skal ta sprøyten.

Selve vaksinen får du som et nålestikk i armen. Stikket kjenner du med en gang. Kanskje gjør det litt vondt også mens vaksinen blir satt. Du blir sikkert overrasket over hvor raskt det går over, og hvor lite du faktisk kjenner. Hvis du har fătt bedøvelsessalve, kjenner du nok ingenting.

Nålen trekkes raskt ut, og den som vaksinerer deg, setter et lite plaster over vaksinestedet.

Når vaksinen er satt, blir du fortalt om de vanlige ettervirkningene: Vondt på stikkstedet, trøtthet, hodepine, vondt i kroppen, frysninger og feber. Bivirkningene er ubehagelige, men går over etter få dager.

Du må vente i 20-30 minutter før du forlater vaksinestedet. Dette er standard prosedyre i tilfelle du skulle få en uventet allergisk reaksjon. Allergiske reaksjoner er sjeldne. Får du en allergisk reaksjon, vet vaksinepersonalet nøyaktig hva de skal gjøre.»

\section{Vær rolig og vennlig}

Følelser og oppførsel smitter lett over på andre. Hvis du som skal sette vaksinen, er avslappet, vennlig og respektfull, kan det ha en beroligende virkning på den som skal vaksineres. Noen av de som skal vaksineres, vil være vaktsomme på alt du gjør. Du kan berolige dem med å forklare enkelt det som skjer.

\section{$\equiv$ «Noen ønsker absolutt ikke forsøk på distraksjon.»}

Du kan også starte en vennlig samtale, slik at oppmerksomheten ledes bort fra prosedyren. Men noen $\varnothing$ nsker absolutt ikke fors $\varnothing \mathrm{k}$ på distraksjon, og da er det viktig at du respekterer det.

Gi alltid beskjed når du går i gang med selve vaksinasjonsprosedyren: «Nå er jeg klar til å sette vaksinen, og nå kommer det et stikk.» 


\section{Vurder lokalbedøvende salveplaster}

For alle med så sterk frykt at det kan føre til at vaksinen ikke tas, anbefaler vi å tilby å dempe stikksmerten med lokalbed $\varnothing$ velse. Dette gis i form av bed $\varnothing$ velseskrem eller bedøvelsesplaster (Emla). Emla-plaster er et reseptfritt legemiddel med to lokalbedøvende substanser (lidokain og prilokain).

Plasteret brukes i samråd med helsepersonell som lokalbedøvelse på huden før nålestikk og mindre hudoperasjoner. Riktig bruk av plasteret forårsaker midlertidig følelsesløshet eller nummenhet i huden på eller i nærheten av påføringsområdet, mens trykk og berøring fortsatt kan føles. Plasteret skal plasseres over innstikkstedet om lag en time før vaksinen skal settes.

Du kan også dempe smerten ved å stryke huden nær injeksjonspunktet (10).

\section{Prøv tanke- eller pusteteknikker}

Du kan forklare dem som har sterk frykt for vaksinasjonen, hvordan de kan bruke tankene til å mestre situasjonen. Det er en fordel om slik instruksjon gis en av dagene før vaksinasjonen.

«Støttetanker» er tanker som hjelper oss til å dempe frykten, og som kan øves inn på forhånd. Det er fint om personen selv kan komme med eksempler på hva som kan hjelpe å si til seg selv. Her er noen eksempler:

- Jeg kan klare det.

- Det kommer til å gå fint.

- Jeg kan se bort og tenke på noe annet.

- Når jeg er ferdig, skal jeg gi meg selv en belønning.

Pusteteknikker kan bidra til å roe dem som har sprøytefrykt. Her er en slik metode:

«Pust inn gjennom nesen mens du teller sakte til fem. Pust inn så kraftig at du kan høre at pusten din går inn. Hold så pusten mens du teller sakte til fem. Pust så rolig ut gjennom munnen mens du teller til seks eller sju (altså litt lenger enn du pustet inn). Vent mens du teller sakte til fem igjen, og deretter gjentar du teknikken noen ganger.» 
La personen prøve noen ganger. Minn vedkommende på å

gjøre det rett før vaksinasjonen.

\section{Prøv distraksjonsteknikker}

Distraksjonsteknikker kan også være nyttige. Da ledes oppmerksomheten bort fra prosedyren til noe i rommet eller en historie du forteller. Å spille et dataspill, se på en video på Youtube eller spille ens favorittmusikk kan være gode kilder til distraksjon.

Noen kan la seg distrahere av et lesebrett eller et spill på mobiltelefonen. Mentale bilder kan også brukes for å distrahere seg selv, som å forestille seg en hyggelig situasjon fra en ferie eller et favorittsted.

\section{Ved angst for å besvime}

For å redusere svimmelhet og risikoen for å besvime ved blodfobi kan man fors $\varnothing$ ke en kroppsspenningsteknikk for å $\varnothing$ ke blodtrykket (13).

Be personen om å oppføre seg som en kroppsbygger som viser frem muskelmassen sin ved å spenne de store muskelgruppene i kroppen: legger, lår, bak, mage, armer, bryst og rygg, så mye som han eller hun kan i 10-15 sekunder. Så skal personen stå eller sitte som normalt, men uten å slappe av i 20-25 sekunder, før en ny periode med muskelspenning starter.

Prosedyren gjentas fem ganger. Det er best å trene på metoden i en ukes tid, helst fem ganger daglig, samtidig som man lærer å kjenne de første tegnene på redusert blodtrykk (svimmelhet, kaldsvette, bli blek og piping i ørene). Øvelsen gir dem et hjelpemiddel mot svimmelheten og en styrket opplevelse av kontroll. Den kan brukes av både barn og voksne.

\section{$\equiv$ ¿Bruk aldri tvang eller press mot dem som er ekstremt redde.»}

Det kan være til hjelp for dem som blir svimle, å sitte med hodet mellom bena og puste dypt og langsomt, eller å legge seg ned på en benk eller på golvet. 
Bruk aldri tvang eller press mot dem som er ekstremt redde.

Du kan gjøre situasjonen verre hvis du reagerer negativt, bagatelliserer, moraliserer eller legger press. Noen kan være så ekstremt redde at de sier de ikke makter å ta vaksinen selv om de vil.

Ta heller et skritt tilbake, ros dem for å prøve. Planlegg en ny time, bruk mer tid på forberedelse og instruksjon i teknikker for å redusere angst, eller planlegg sammen for bruk av lokalbedøvelse i form av salveplaster.

Vurder også om det er aktuelt å henvise videre for behandling av blod- og injeksjonsfobi, med vekt på systematisk eksponeringstrening $(14,15)$.

\section{La den enkelte få valg i situasjonen}

Det er lettere å gjennomføre vaksinasjonen hvis den som skal vaksineres, opplever en viss egenkontroll med det som skal skje. Når vi er redde, er det viktig å bli møtt med forståelse og vennlighet. Du kan for eksempel si:

«Jeg har skjønt at du har grudd deg, og jeg vet at mange engster seg for å ta sprøyte. Men jeg er her for å hjelpe deg, og sammen skal vi få det til. Hva er best for deg - vil du at jeg skal forklare nøye hva jeg konkret gjør eller ikke? Vil du sitte eller helst ligge?

Noen vil se på armen, mens andre heller vil la blikket hvile på noe annet her i rommet. Hva er best for deg? Og du bestemmer selv i hvilken arm vi skal sette vaksinen.»

\section{三《Det kan være en stor personlig seier å gjennomføre vaksinasjonen for en med stor frykt.»}

$\varnothing \mathrm{kt}$ egenkontroll $\varnothing$ ker sjansen for mestring av frykt og et vellykket resultat. Personen kan for eksempel selv gå på apoteket og kjøpe et reseptfritt bedøvelsesplaster.

Salveplasteret settes på det avtalte stikkstedet en time før neste vaksineavtale.

Tenk på den som skal vaksineres, som en samarbeidspartner som i størst mulig grad selv velger hvordan situasjonen skal være, ut fra hans eller hennes erfaringer om hva som hjelper mot frykten. 


\section{Gi anerkjennelse}

Husk å gi anerkjennelse når noen trosser frykten og klarer å gjennomføre vaksinasjonen. Spør gjerne hvordan det var, og lytt aktivt til tilbakemeldingen du får. Lytt også til hva de lærte, for eksempel at nålestikket bare var litt smertefullt, eller at smertene raskt gikk over. Spør om du får bruke deres erfaring når du skal forberede andre som er redde for prosedyren.

Det kan være en stor personlig seier å gjennomføre vaksinasjonen for en med stor frykt. En slik erfaring kan gjøre neste nålestikk mindre skremmende.

\section{Noen nyttige nettressurser}

- Folkehelseinstituttet, vaksinasjonsveileder for kommuner og helseforetak

- Engelskspråklig nettsted med nøktern informasjon om sprøytefobi: needlephobia.com

- Informasjon til helsepersonell, «Hvordan kan redsel for å ta vaksine håndteres?»

- Informasjonshefte til pasienter, «Å være redd for sprøyter og blod»

\section{Referanser}

1. Folkehelseinstituttet. Koronavaksine. Informasjon til helsepersonell. Tilgjengelig fra: https://www.fhi.no/nettpub/vaksinasjonsveilederen-forhelsepersonell/vaksiner-mot-de-enkeltesykdommene/koronavaksine/ (nedlastet 17.01.2021).

2. McLenon J, Rogers MAM. The fear of needles: a systematic review and meta-analysis. J Adv Nurs. 2019;75(1):30-42. DOI: 10.1111/jan.13818

3. Wright S, Yelland M, Heathcote K, Ng S-K. Fear of needles - nature and prevalence in general practice. Aust Fam Physician. 2009;38:172-6.

4. Bienvenu OJ, Eaton WW. The epidemiology of bloodinjection-injury phobia. Psychol Med. 1998;28:1129-36.

5. Wani AL, Ara A, Bhat SA. Blood injury and injection phobia: the neglected one. Behav Neurol. 2014;47:13-4O. DOI: $10.1155 / 2014 / 471340$ 
6. Lilliecreutz C, Sydsjö G, Josefsson A. Obstetric and perinatal outcomes among women with blood- and injection phobia during pregnancy. J Affect Disord. 2011;129:289-95.

7. Van Houtem CMHH, Laine ML, Boomsma DI, Ligthart L, van Wijk AJ, De Jongh A. A review and meta-analysis of the heritability of specific phobia subtypes and corresponding fears. J Anxiety Disord. 2013;27:379-88. DOI:

10.1016/j.janxdis.2013.04.007

8. Olatunji BO, Williams NL, Sawchuk CN, Lohr JM. Disgust, anxiety and fainting symptoms associated with blood-injection-injury fears: a structural model. J Anxiety Disord. 2006;20:23-41.

9. Ritz T, Meuret AE, Simon E. Cardiovascular activity in blood-injection-injury phobia during exposure: evidence for diphasic response patterns? Behav Res Ther. 2013;51:460-8. DOI: $\underline{\text { 10.1016/j.brat.2013.03.011 }}$

10. Friedrichsdorf SJ, Goubert L. Pediatric pain treatment and prevention for hospitalized children. Pain Rep. 2020;5(1):e804. DOI: 10.1097/PR9.0000000000000804

11. Taddio A, Chambers CT, Halperin SA, Ipp M, Lockett D, Rieder MJ, et al. Inadequate pain management during routine childhood immunizations: the nerve of it. Clin Ther. 2009;31 Suppl 2;S152-67. DOI: 10.1016/j.clinthera.2009.07.022

12. Folkehelseinstituttet: Koronavaksine på 1-2-3 - på ulike språk. Tilgjengelig fra:

https://www.fhi.no/publ/informasjonsark/koronavaksine-pa-12-3/ (nedlastet 17.01.2021).

13. Öst LG, Strener U. Applied tension. A specific behavioral method for treatment of blood phobia. Behav Res Ther. 1987;25:25-9. DOI: 10.1016/0005-7967(87)90111-2

14. Berge T, Fjerstad E. Sprøyteskrekk kan kureres. Sykepleien. 2012;13:58-61. Tilgjengelig fra: https://sykepleien.no/forskning/2012/10/sproyteskrekk-kankureres (nedlastet 29.01.2021).

15. Berge T, Fjerstad E, Hyldmo I, Lang N. Håndbok i klinisk helsepsykologi. Kapittel 14. Behandling av spesifikke fobier: blod-, skade- og injeksjonsfobi. Bergen: Fagbokforlaget; 2019. 
